\title{
Iodine biofortification of vegetable plants-An innovative method for iodine supplementation
}

\author{
WENG HuanXin ${ }^{1 *}$, HONG ChunLai ${ }^{1,2}$, XIA TianHong ${ }^{1}$, BAO LiTing $^{1}$, LIU HuiPing $^{1} \&$ \\ LI DeWang ${ }^{1}$ \\ ${ }^{1}$ Institute of Environment \& Biogeochemistry, Zhejiang University, Hangzhou 310027, China; \\ ${ }^{2}$ Agriculture Science Research Institute in Zhejiang Province, Hangzhou 310021, China
}

Received February 14, 2012; accepted April 26, 2012; published online February 25, 2013

\begin{abstract}
To elevate the iodine level in edible plants has been shown to be an excellent approach to correct iodine deficiency. We have proposed an innovative approach to produce iodine supplementation by growing vegetables on soils with algal-based iodized organic fertilizer. Ten species of vegetables were tested. The biological absorption and migration of the iodine within the vegetable plants were revealed using microscopy with silver iodide precipitation technique. The results show that the absorption of iodine by the vegetable increases with increasing amount of the algal-based iodized organic fertilizer in general. And the uptake of iodine by leaf vegetable is significantly greater than that by fruit vegetable. Distribution of iodine in various plant organs shows a trend of decreasing iodine concentration from root, leaf, stalk, to fruit. A similar of decreasing concentration can also be found in various cells (cytoplasm>cytoderm>organelles). The exploration of the iodine uptake and biogeochemistry migration mechanisms provides an important scientific foundation for establishing a new method of producing a natural iodine supplementation by iodine biofortification of vegetables.
\end{abstract}

edible plant iodine, IDD, natural iodine supplementation

Citation: Weng H X, Hong C L, Xia T H, et al. Iodine biofortification of vegetable plants-An innovative method for iodine supplementation. Chin Sci Bull, 2013, 58: 2066-2072, doi: 10.1007/s11434-013-5709-2

Iodine is an essential microelement, which plays an irreplaceable role in metabolism process [1]. Iodine deficiency will cause inadequate synthesis of thyroid hormone that has multiple functions such as enhancing protein synthesis, regulating energy transfer, accelerating growth and development, and maintaining the structure of central nervous system. The resulted physiological disorders and biological function abnormalities are called iodine deficiency disease (IDD) [2-5]. The epidemiology investigations and the statistics from World Health Organization (WHO) reveal that iodine deficiency, due to low iodine background value in certain regions, is a threat to health of up to 1.6 billion people throughout the world [6,7]. China alone, there are 425 million people live in iodine deficiency environment. It is

*Corresponding author (email: gswenghx@zju.edu.cn) estimated that iodine deficiency account for $80 \%$ of the mental handicapped cases in China. Given the risk factor of IDD to the health of people, iodine supplementation is definitely a very important public health issue faced by the world.

Two main sources of iodine supplementation are seafood and iodized salt. Taking seafood is an excellent iodine supplementation method but is hardly to meet the needs in most iodine deficient area (usually inland) because of economic obstacles and food preference. As a result, iodized salt is a widely used prophylaxis for IDD [8]. Since the beginning of 1990s, the Chinese government started a universal iodized salt program, which effectively made almost all salt sold in China, were iodized at a higher level than the international standard suggested by WHO in afraid of that much of the iodine will be lost during higher temperature cooking practiced in Chinese culture. This seemly overdose policy even- 
tually results in a higher intake per capital compared with the standard of 150-200 $\mu \mathrm{g} / \mathrm{g}$ for adult recommended by WHO [6,9]. It is well known, however, that iodine is characterized with bilateral threshold. Either overdose of iodine or deficiency of iodine can cause adverse effects [10]. There are reports that the number of hypothyroid patients in hospital increased by $0.3-3.0$-fold after the initiation of the universal iodize salt program [11]. On the other hand, however, once the iodized salt was unavailable, the morbidity of IDD would rebound in those iodine deficiency areas. Clearly, the approach of using iodine salt has a significant flaw due to uncertainty in bioavailability of iodine.

The $80 \%$ of the iodine in human body and animal original come from edible vegetable food under nature condition $[12,13]$, and the bioavailability of iodine in food can achieve as much as $99 \%$. Due to the fact that iodine in edible plant food originates from soil, the background concentration of iodine in soil as well as its bioavailability determines whether the consumed iodine can meet the need. The iodine concentration in soil is estimated to be between $1.55-12.93 \mathrm{mg} / \mathrm{kg}$ in China [14]. The iodine concentrations in both the soils and the vegetables in inland are usually too low to meet the need of the human body. Apparently, to elevate the concentration of iodine in soil and thus enrich iodine in edible plant food using iodine fertilizers is an attractive approach for producing iodine supplementation and eliminating IDD because of its natural prevention of overdose and readily fitting in local food chain. Hydroponic experiments and pot study [15-17] has shown that crop root can assimilate exogenous iodine effectively in some concentration range. Field research, however, was seldom conducted and the process of absorption and accumulation of exogenous iodine is almost unknown. In this study, we have cultivated iodine-containing vegetables directly by adding algal organic iodized fertilizer into soil and thus realized iodine biofortification of edible vegetable. Using microscopy [18] and localization techniques, we have identified and analyzed the distribution of intracellular iodine which revealed the absorption mechanism of iodine by edible vegetable. The findings show that iodine biofortification is a promising approach for eliminating IDD.

\section{Materials and methods}

We have selected 10 common vegetables as testing plants, among which there are two groups: leaf vegetable and fruit vegetable. The leaf vegetable consists of spinach, cabbage, coriander, potherb mustard, and Chinese cabbage whereas the fruit vegetable includes tomato, cucumber, long cowpea, eggplant, and hot pepper.

The paddy soil, a typical soil for vegetable produce in Hang-Jia-Hu plain of Yangtze River Delta region were used in our experiment. Basic physical and chemical properties of the soil are given in Table 1.

The algal organic iodized fertilizer used in the experiment was made from iodine-rich algae and diatomite [19]. The iodine concentration of algae is about $1 \%-2 \%$ of its dry weight. Diatomite has excellent adsorption capability which enhances absorption of iodine contributes to a preferred slow releasing of iodine [20]. The iodine concentration of algal organic iodized fertilizer is about $1087 \mathrm{mg} / \mathrm{g}$, mostly in soluble state which is highly bio-available.

\subsection{Field experiments}

Seeds of cabbage and Chinese cabbage were treated with $1 \%$ potassium permanganate solution for 14-16 min followed by a thoroughly rinsing and then sowed on seedbed. The seeds will be kept in seedbed until the germinated seeds grew 4-6 leaves. The seeds of spinach and coriander were soaked in cold water for 22-24 h (replacing water once in the process). Two to three days after the seeds germinates at temperature of $4-5^{\circ} \mathrm{C}$, they were sowed in seedbed. Potherb mustard seeds were distributed evenly in plough and covered by straws to maintain soil moisture and promote germination and emergency of the seeds. The thinning was done when 1-2 true leaves sprouted. The final singling was established as 5-6 true leaves sprouted and the plant grew up to $10-13 \mathrm{~cm}$. The seeds of coriander was immersed into water for 24-30 $\mathrm{h}$ and then germinated at the temperature of $20-25^{\circ} \mathrm{C}$. We sowed the seeds and covered them with $1.5-$ 2-cm-thick fine soil in plough. The plant ash, straw and wheat straw were used to cover the plough. The thinning and final singling were established same as above.

(2) Seeds of tomato, long cowpea, eggplant and hot pepper were treated with $1 \%$ potassium permanganate solution for $20 \mathrm{~min}$ and the cucumber seeds were disinfected with $0.1 \%$ carbendazim solution for $10 \mathrm{~min}$. The long cowpea seeds were sowed directly after disinfection treatment. We selected 1-2 robust seedlings for every single hole after thinning and final singling. All other seeds were germinated first and then sowed in greenhouse seedbeds which were covered by fine soil. After 4-5 leaves sprouted, the plants were collected and transplanted to plough.

(3) The field soil was initially amended with base manure before sowing. The algal organic iodized fertilizer was applied into soil surface before sowing. Two sets of fertilizer

Table 1 Characterizations of the experimental soils

\begin{tabular}{cccccccc}
\hline Soil type & Total N $(\mathrm{g} / \mathrm{kg})$ & Total P $(\mathrm{g} / \mathrm{kg})$ & Total K $(\mathrm{g} / \mathrm{kg})$ & $\mathrm{CEC}(\mathrm{mol} / \mathrm{kg})$ & Organic matter $(\mathrm{g} / \mathrm{kg})$ & $\mathrm{pH}$ & Iodine background $(\mathrm{mg} / \mathrm{kg})$ \\
\hline Paddy soil & 2.56 & 0.704 & 16.8 & 19.28 & 40.9 & 5.91 & 2.02 \\
\hline
\end{tabular}


with different amount of iodine were used. For leaf vegetables, there were five application levels of iodine $(12,25,50$, $100,150 \mathrm{mg} / \mathrm{m}^{2}$ ) whereas four application levels of iodine $\left(12,35,70,150 \mathrm{mg} / \mathrm{m}^{2}\right)$ for fruit vegetables. Compound fertilizer (NPK) was applied twice during growth season. In the plot, a zero treatment (i.e. without any iodine application) was included also as a reference.

\subsection{Chemical and statistic analysis}

The vegetables were harvested when they reached the stage qualified to be traded on market. The test samples were rinsed in deionized water and blotted dried. Fresh weights of root, stalk, leaves and fruit were determined afterward. The iodine levels of vegetable tissues were measured after being dried at a constant temperature of $50^{\circ} \mathrm{C}$ and shivered through 120 meshes.

(i) Iodine determination and cell separation. Following the differential centrifugation procedure initially introduced by Weigel et al. [21] we applied differential centrifugation on homogenized tissue and separated the cells of vegetables strengthened by exogenous iodine $\left(150 \mathrm{mg} / \mathrm{m}^{2}\right)$ into indissoluble cytoplasm, cytoderm and organelle. The details of the procedure are shown in Figure 1.

The homogenate consists of sucrose $(250 \mathrm{mmol} / \mathrm{L})$, dithioerythritol $(1 \mathrm{mmol} / \mathrm{L})$ and Tris buffer $(50 \mathrm{mmol} / \mathrm{L}, \mathrm{pH}$ 7.0). The iodine concentration of all tissues was determined by ICP-MS. Three duplicates were used for each sample. The results presented are mean value of the duplicates.

(ii) Microscopy analysis. On the fact that halogen and silver generate precipitation, we can investigate the distribution of iodine in vegetables thoroughly by microscopy.

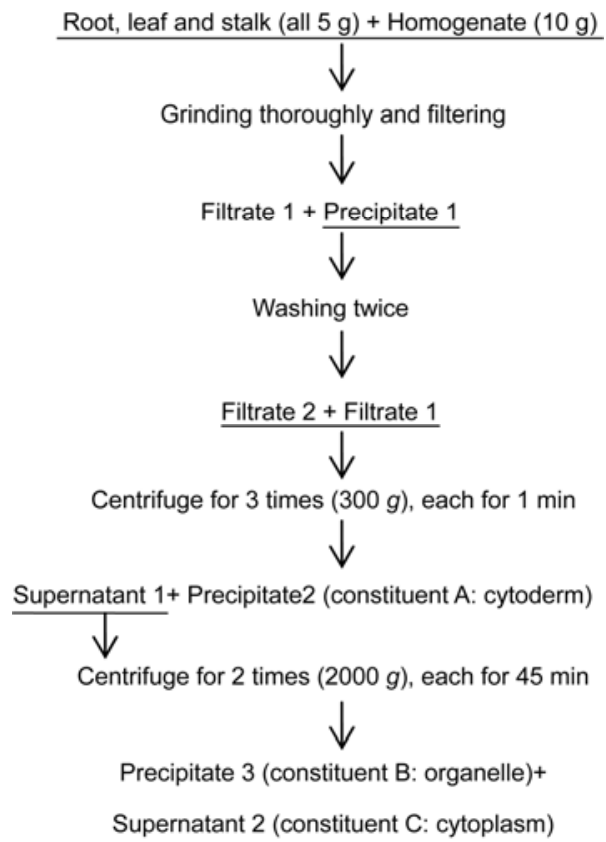

Figure 1 Schematic diagram of the procedure for separating cytoplasm, cytoderm and organelle of cells.
The samples were cleaned, dried, and then cut into $1 \mathrm{~mm}^{3}$ cube-like pieces. The procedures thereafter are shown below.

(1) The samples of root, stalk and leaves are fixed in cacodylate buffer solution at different concentrations $(0.1$, $0.3,0.5 \mathrm{~mol} / \mathrm{L}$ respectively) for $2 \mathrm{~h}$ at temperature of $4^{\circ} \mathrm{C}$ and the $\mathrm{pH}$ is maintained at 7.2.

(2) Dumping the fixative, washing each tissues in cacodyl buffer solution for three times, each $15 \mathrm{~min}$. Dewatering samples for 15 min with $50 \%$ tertiary butanol solution and then with ethanol solution of different concentration (50\%, $70 \%, 80 \%, 90 \%, 95 \%)$ successively (75 min altogether). The tissues are treated with $100 \%$ ethanol solution for 20 min and then embedded after treating with pure acetone solution for $20 \mathrm{~min}$.

(3) The samples are then treated with mixtures of embedding medium and acetone solution $(\mathrm{v} / \mathrm{v}=1 / 1,3 / 1)$ for 1 and $3 \mathrm{~h}$ respectively. Chemical pure embedding medium is used to treat the sample overnight which was then embedded at $70^{\circ} \mathrm{C}$ overnight to obtain excellent embedded sample. The samples are cut into sections with a thickness between $70-90 \mathrm{~nm}$ using ultramicrotome. The sections are dyed with lead citrate solution, uranium acetate solution and 50\% ethanol solution for $15 \mathrm{~min}$, respectively. Once all procedures are completed, the sample sections are ready for observation under TEM. The root sections which can not be dyed are analyzed by $\mathrm{X}$ transmission electron microscopy.

\section{Results and discussion}

\subsection{Iodine uptake}

The iodine concentrations in both leaf vegetable and fruit vegetable increased significantly compared to those treated with zero iodine application. Such increase is proportional to the amount of algal organic fertilizer applied. The exogenous iodine can be uptake effectively by vegetables (Figures 2 and 3 ).

However, iodine uptake by leaf vegetable was more significant than that by fruit vegetables for given application

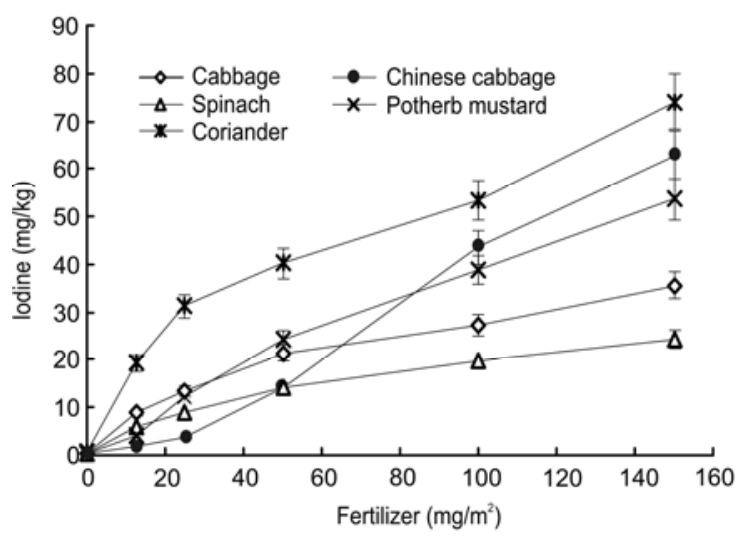

Figure 2 Iodine concentration of edible part of leaf vegetables against fertilizer application. 


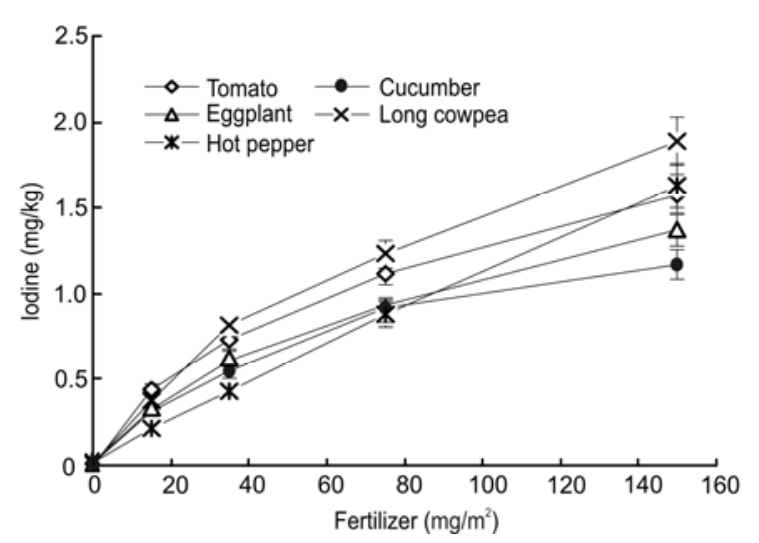

Figure 3 Iodine concentration of edible part of fruit vegetables against fertilizer application.

intensity. At the same level of application of $150 \mathrm{mg} / \mathrm{m}^{2}$ iodine, the total uptake of iodine by leaf vegetable was 50 70 -fold higher than that by fruit vegetables. Furthermore, the responses of the leaf vegetables to the iodine fertilizer were also different, depending on the application intensity. At a low case $\left(<50 \mathrm{mg} / \mathrm{m}^{2}\right)$, the iodine level in cabbage and Chinese cabbage was greater than that in spinach. At a high case $\left(>100 \mathrm{mg} / \mathrm{m}^{2}\right)$, however, the uptake of iodine by spinach was more than the other leaf vegetables. It was observed that the uptake of exogenous iodine was controlled by both the intensity of the iodine fertilizer application and the individual characteristics of the plant. Unlike the leaf vegetable, the variations of the fruit vegetables were less visible than that of the leaf vegetables.

Iodine concentration in root was significantly correlated with that in leaf $\left(R^{2}=0.96-0.99\right.$, leaf vegetables $)$, which indicated that exogenous iodine absorbed by root was proportionally transferred to leaf (Figure 4).

Similar correlation could also be found in the fruit vegetables (Figure 5; root-fruit, $R^{2}=0.94-0.99$ ) although it was less significant than that shown in Figure 4, indicating that exogenous iodine absorbed from soil could be transferred to fruit via stalk but iodine concentration in edible tissues

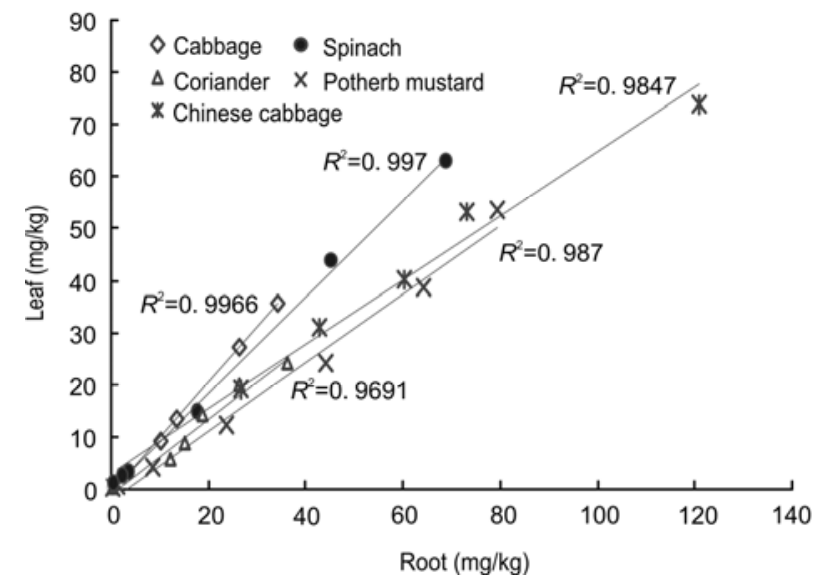

Figure 4 Iodine in root against in leaf (leaf vegetables).

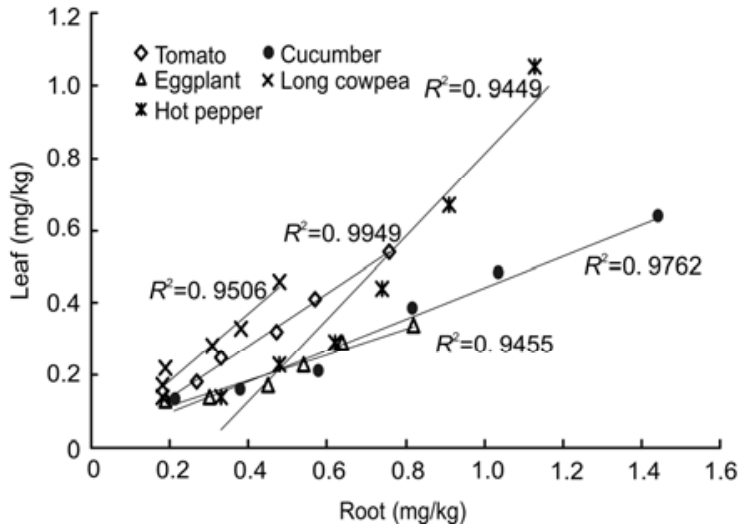

Figure 5 Iodine in root against in leaf (fruit vegetables).

could be limited by the gateway of metastasis.

Previous researches had demonstrated that edible plant was perfect for regulating the amount of necessary microelements in human body. Microelements absorbed and transferred to biological active state by some biochemical reaction can be assimilated efficiently by human body [22]. Iodine in plant food was totally safe without any side effect and was easier to be used compared with iodized salt and synthetic iodized tablet $[13,23]$. Our results revealed that the iodine concentration in edible parts of fresh spinach, cabbage, coriander, potherb mustard and Chinese cabbage can reach as high as $0.45,2.28,4.83,1.45,1.05 \mathrm{mg} / \mathrm{kg}$ (fresh weight, FW), respectively, if the application of fertilizer reaches $12 \mathrm{mg} / \mathrm{m}^{2}(1.8,9.1,19.3,5.8,4.2 \mathrm{mg} / \mathrm{g}$ (dry weight), respectively, taking the moisture content of fresh vegetables as $75 \%$ ). According to the standard uptake amount of iodine recommend by WHO [6], an adult could take 31-333 g such iodized leaf vegetables daily to meet the necessary amount of iodine $(150 \mu \mathrm{g} / \mathrm{d}$ for adult, $200 \mu \mathrm{g} / \mathrm{d}$ for pregnant and lactating women), which is not a difficult task. For fruit vegetables (taking the application intensity of $75 \mathrm{mg} / \mathrm{m}^{2}$ as an example), the iodine concentration in the fruits of eggplant, hot pepper, cucumber, tomato and long cowpea reached $1.23,0.88,0.91,1.12$ and $0.92 \mathrm{mg} / \mathrm{kg}(\mathrm{FW})$, respectively. Meanwhile the corresponding values in leaf and stalk were 15.56, 21.30, 10.48, 7.74 and $8.42 \mathrm{mg} / \mathrm{kg}$ (FW). When human consume fruit vegetables, the stalk and leaf can be utilized as food for poultry and livestock, which would eventually, elevate the background value of iodine in food chain and remediate the iodine-poor environment.

\subsection{Distribution of iodine}

The distribution of iodine in the testing vegetables was analyzed and are shown in Figures 6 and 7.

For leaf vegetables, the iodine concentration in root was greater than that in leaf in general and such difference in concentration is more significant when the exogenous iodine application increased to a higher level except for cabbage and spinach, which show almost identical concentrations in root 


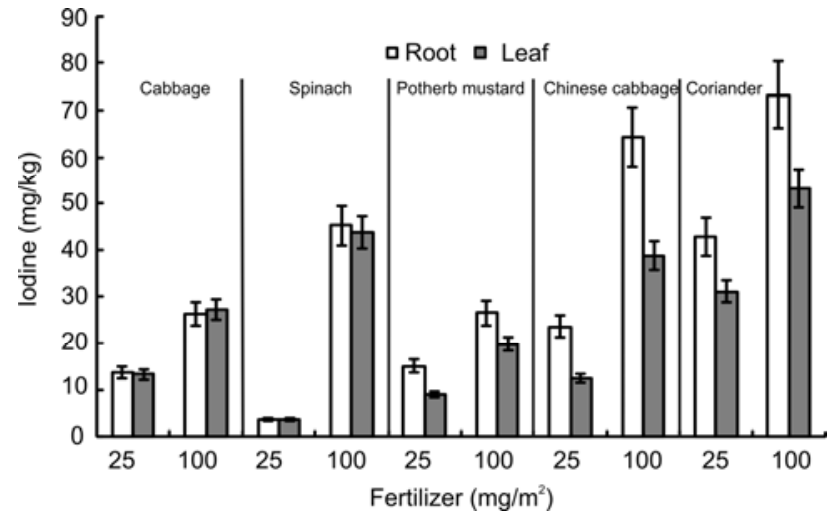

Figure 6 Characterization of distribution of iodine in leaf and root (leaf vegetables).

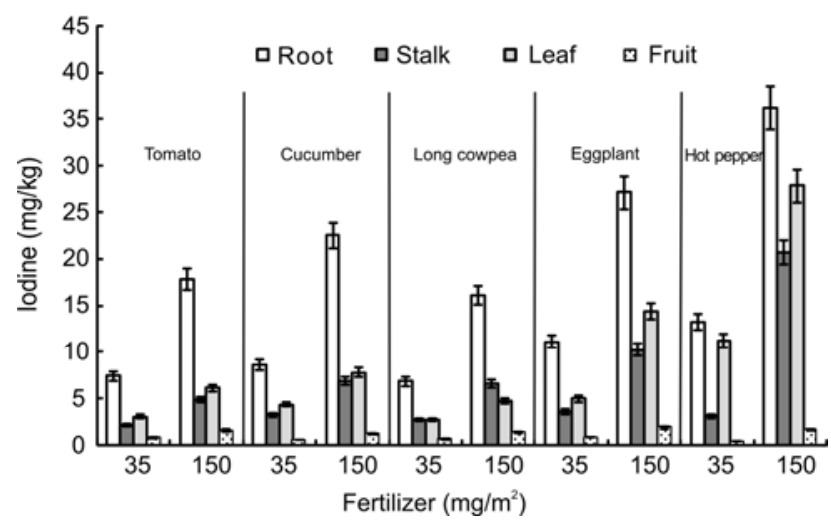

Figure 7 Characterization of distribution of iodine in leaf and root (fruit vegetables). and leaf. For fruit vegetables, the concentration of iodine in root was usually the largest and that in fruit was smallest.

When the application of fertilizer increased threefold, as shown in Figures 6 and 7, there was a corresponing increase of iodine concentraton in leaf and fruit only by 1-2 times both for leaf vegetable and fruit vegetalble. However, the response to the increase of the iodine fertilizer was much greater as showed by a 11-fold increase in concentration in both leaf and root.

The relative concentration of iodine in organs is shown in Figure 8. Iodine was mostly concentrated in cytoplasm and less in organelle.

Cytoderm, as shown in Figure 7, however, had a moderate concentration of iodine. $57.82 \%$ of the absorbed iodine was in cytoplasm (ranging from $39.78 \%$ to $76.87 \%$ ) whereas only $28.57 \%$ in cytoderm (ranging from $14.12 \%$ to $40.18 \%$ ) and $13.61 \%$ in organelle (ranging from $3.63 \%$ to $24.27 \%$ ). Furthermore, much higher iodine concentration was observed in root cells than that in leaf or stalk cells. It implies that the concentration gradient is the third force to drive the iodine migrating from the root to stalk and leaf through diffusion besides the transpiration pull and root pressure (both advection movements).

\subsection{Uptake and transfer of iodine}

To identify the exact location of iodine in cells from a micro perspective and further characterized biological absorption and migration of iodine by vegetables, we investigated the iodine distribution in the cabbage (algal organic iodized fertilizer at $150 \mathrm{mg} / \mathrm{m}^{2}$ ) with TEM, as an example. Figure 9

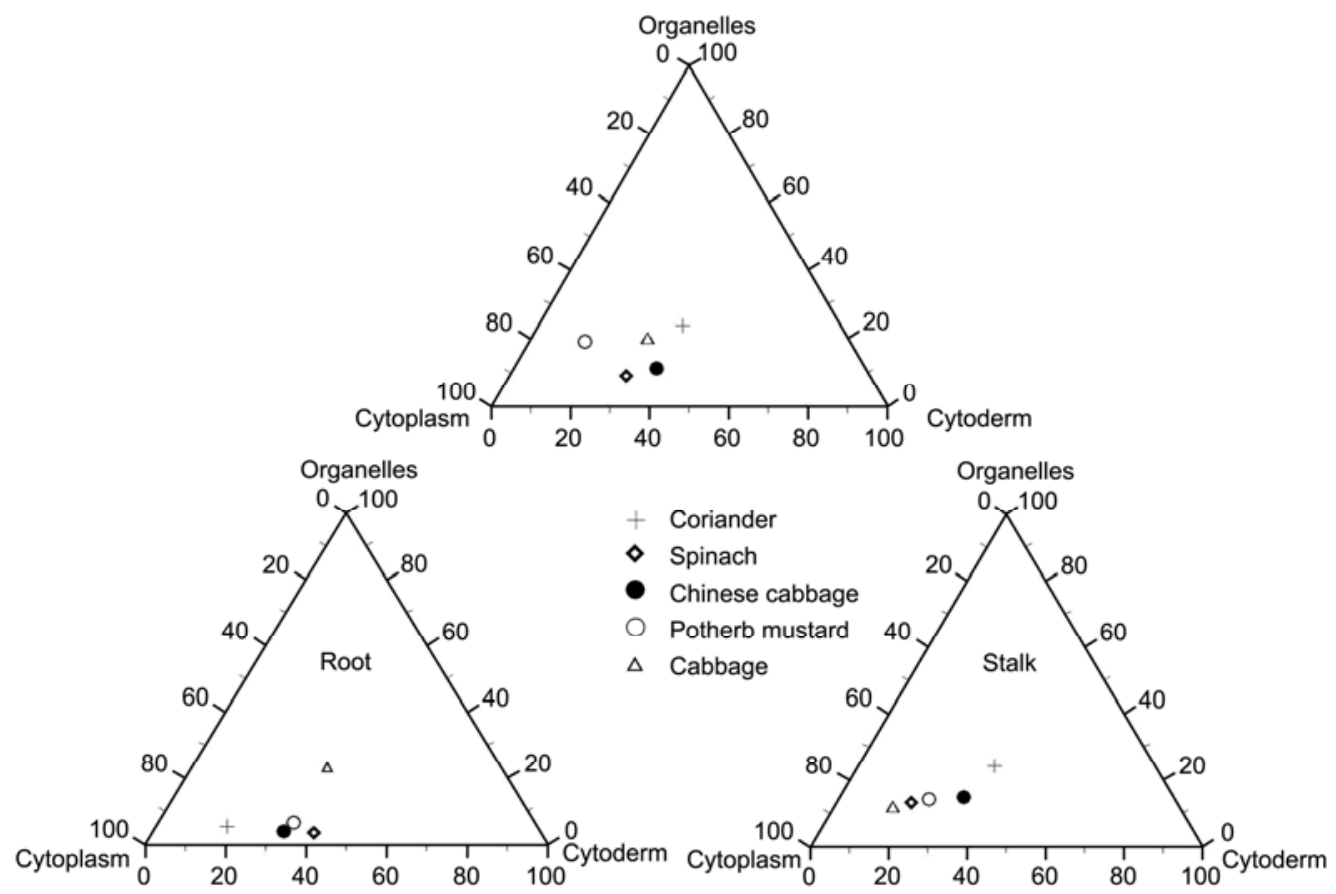

Figure 8 Relative concentration of iodine in cytoplasm, cytoderm and organelle (stalk, leaf, root cell, leaf vegetable). 

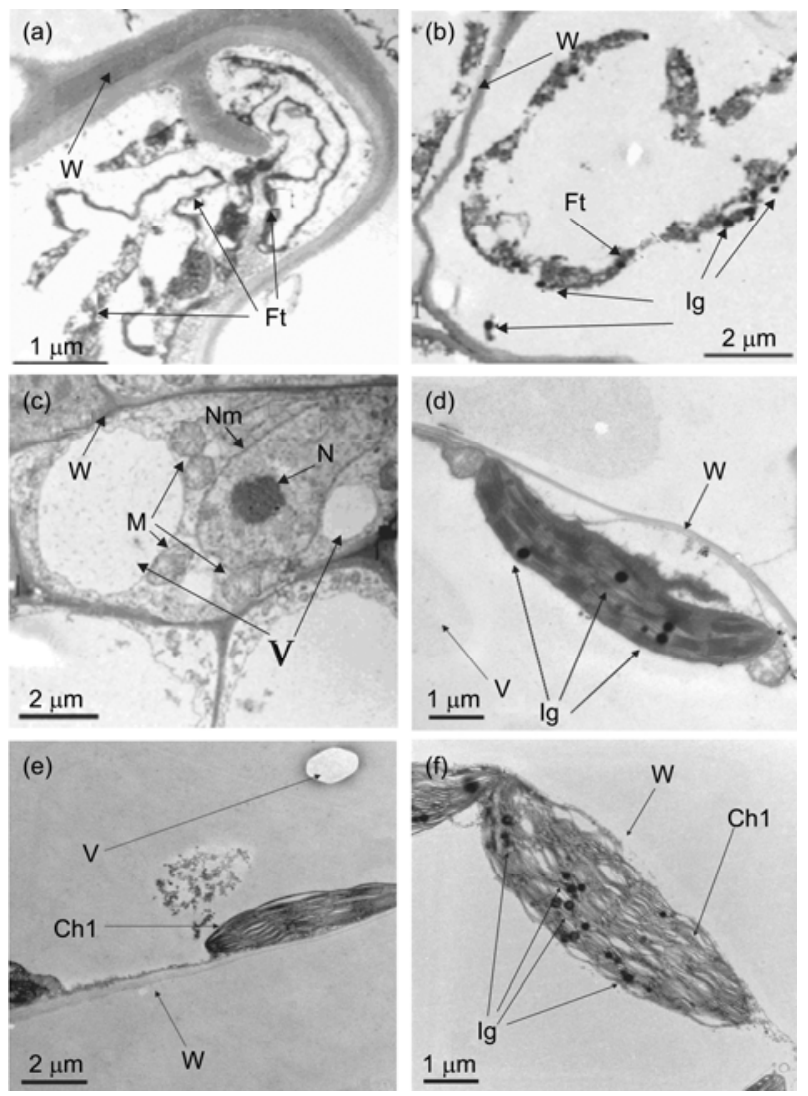

Figure 9 TEM micrographs of cells of cabbage (control group and experiment group). (a) Root cell (control group, $\times 8000$ ); (b) root cell (experiment group, $\times 60000$ ); (c) stalk cell (control group, $\times 12000$ ); (d) stalk cell (experiment group, $\times 20000$ ); (e) leaf cell (control group, $\times 12000$ ); (f) leaf cell (experiment group, $\times 20000$ ). Chl, Chloroplast; Ft, fibrous tissue; I, intercellular space; Ig, AgI; M, mitochondria; N, nucleus; Nm, nuclear membrane; V, vacuole; $\mathrm{W}$, cytoderm.

is TEM micrographs of cabbage cells.

TEM showed dark precipitates in cells (fruit, root and leaf) of the plant with iodine fertilizer. For those cells of the plant with no iodine fertilizer (the control group), however, the precipitate did not exist. Hence, we can hypothesis that iodine was absorbed and transferred to cells (fruit, root and leaf).

In contrast to root cells of cabbage of control group which no dark precipitates was seen in cytoderm (W) and fibrous tissue $(\mathrm{Ft})$, this precipitates were abundance in that of experiment group (Figure 9(a), (b)). The observation that dark precipitates in fibrous tissue demonstrated, that iodine transferred upward by transpiration was somewhat retarded by fibrous tissue in root.

Figure 9(c) shows a fine structure of stalk cell of cabbage, but no dark precipitates could be seen. The cabbage treated with iodine-containing fertilizer (Figure 9(d)), however, had the dark precipitates in chloroplast, the cells where photosynthesis and metabolism takes place.

Similar results were found in the leaf cell. Chloroplast, cytoderm, vacuole and starch grain could be seen clearly in Figure 9(e), but no dark precipitates there. However, a large amount of dark precipitates existed in the leaf cells of experiment group (Figure 9(f)), which revealed that iodine was also transferred to chloroplast of the leaf cells.

We also used energy dispersive analysis of X-ray (EDAX) to identify the existence of iodine in the cabbage cells. As shown in Figure 10, Ag was detected in the cabbage cells of the control group, but no iodine. In contrast, both $\mathrm{Ag}$ and I were detected in the cabbage cells of the experiment group. This result further proved that the cabbages can uptake exogenous iodine from soil and revealed the exact location of iodine in the cabbage.

Results from EDAX and TEM revealed that the iodine in the root cell of the cabbage was mostly accumulated in fibrous tissue. Meanwhile, much of iodine in the stalk and leaf cells existed in chloroplast. According to previous studies, absorbing mineral elements such as the uptake of iodine by root system could be generally divided into three steps [24]: (1) iodide in soil solution is firstly picked up at the surface of root tissues. (2) Iodide then penetrates the xylem conduit of root tissues. (3) Iodide is transferred upwards with xylem sap by transpiration pull and by root pressure. Iodine was readily retained in root cells due to a large amount of fibrous tissue in root, and the most iodine transferred upwards was accumulated in chloroplast probably because water is a major agent to carry iodine move from root to leaf but evaporate in chloroplast resulting accumulation of iodine there.

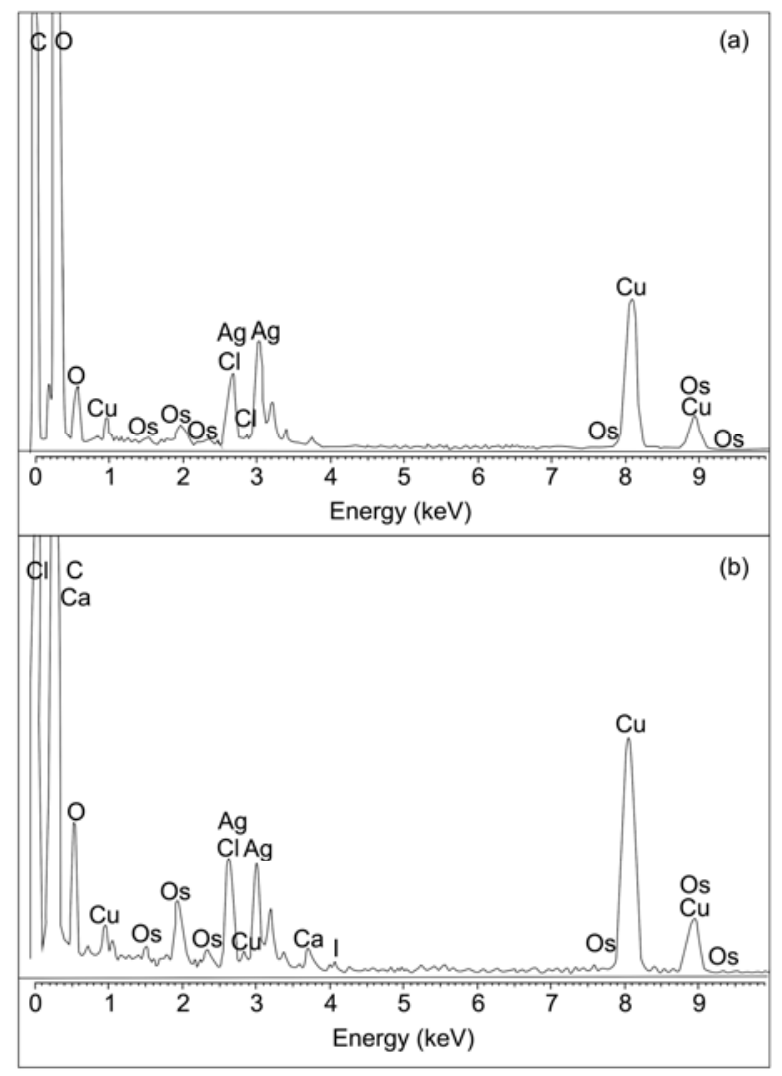

Figure 10 EDAX diagram of section (cabbage cell). (a) Control group; (b) experiment group. 
In general, mean concentration of iodine in cell of leaf vegetables shows a trend of that cytoplasm $>$ cytoderm $>$ organelle (Figure 8). Mean concentration of iodine in organelle of leaf, stalk and root cell is $16.74 \%, 15.65 \%$ and $8.43 \%$ respectively. The iodine concentration in organelle of leaf and stalk cell was significant higher than that of root cell. In cytoderm, however, the corresponding concentrations are $29.16 \%$ (leaf), $24.91 \%$ (stalk) and $31.65 \%$ (root) respectively.

\section{Conclusion}

Both leaf vegetables and fruit vegetables can absorb exogenous iodine from soil. The uptake amounts increases with the application intensity of algal organic iodized fertilizer. However, uptake capacity is different for different vegetable. The leaf vegetables have a greater absorbing capacity than the fruit vegetables, although there are variations in uptake capacity, usually less significant, between different species within the same type vegetables.

There is a significant correlation of iodine concentration either between leaf and root (leaf vegetables, $R^{2}>0.94$ ) or between fruit and root (fruit vegetables, $R^{2}>0.94$ ). In other words, iodine uptake from soil by root system can be continuously transferred to the edible part of vegetables, and they are proportional.

The iodine distribution in vegetable cell shows an order that cytoplasm $>$ cytoderm $>$ organelle. Most iodine in root cells is accumulated in the fibrous tissue whereas the most iodine in stalk and leaf cells is in chloroplast.

Iodine concentration in root is higher than that in leaf. The iodine distribution in fruit vegetables is in an order that root $>$ leaf $>$ stalk $>$ fruit.

Our experimental results show that we can regulate the bioavailability of iodine in vegetables within a reasonable range by changing the application amount of iodine fertilizer to meet the need of human body for iodine. The edible part of vegetables is an excellent option for iodine supplementation and can be readily incorporated into human diet. The iodine in root and soil can be reused for the next generation of vegetable. In addition, the iodine-containing inedible parts like stalk and the leaf of fruit vegetable can be utilized as feed for poultry and livestock. A long term application of algal organic iodized fertilizer will elevate the iodine level in food chain and further improve the ecological condition in iodine deficiency area, and eventually, eliminate the IDD thoroughly.

This work was supported by the National Natural Science Foundation of China (40873058 and 40373043).
1 Gerber H, Peter H J, Bürgi E, et al. Colloidal aggregates of insoluble inclusions in human goiters. Biochimie, 1999, 81: 441-445

2 Chi X Z. Microelement and Health (in Chinese). Beijing: Chemical Industry Press, 1997. 205-211

3 Rose N R, Bonita R, Burek C L. Iodine: An environmental trigger of thyroiditis. Autoimmune Rev, 2002, 1: 97-103

4 Upadhyay G, Singh R, Sharma R, et al. Differential action of iodine on mitochondria from human tumoral- and extra-tumoral tissue in inducing the release of apoptogenic proteins. Mitochondrion, 2002, 2: 199-210

5 Zimmermann M B. Iodine requirements and the risks and benefits of correcting iodine deficiency in populations. J Trace Elem Med Bio, 2008, 22: 81-92

6 Bruno D B, Erin M, Maria A, et al. Iodine deficiency in 2007: Global progress since 2003. Food Nutr Bull, 2008, 29: 195-202

7 Hetzel B S, Delange F, Dunn J T, et al. Towards the Global Elimination of Brain Damage due to Iodine Deficiency. New Delhi: Oxford University Press, 2004. 10-12

8 WHO, UNICEF, ICCIDD. Progress towards the elimination of iodine deficiency disorders (IDD). Geneva: WHO Publication, 1999. 1-33

9 Chen J S, Yang W X, Li N, et al. Salt iodization and risk assessment of iodine status in Chinese population (in Chinese). Technical Report, Ministry of Health of China. 2011

10 Wang $\mathrm{M} \mathrm{H}$, Zhang S. On biogeochemistry areas and endemic disease (in Chinese). Sci China Ser B, 1985, 10: 931-936

11 Jia Y B, Fan H D, Yang X E. Transfer of iodine from environment to human food chain (in Chinese). Guangdong Trace Elem Sci, 2003, 10: $1-12$

12 Delong G R, Leslie P W, Wang S H, et al. Effect on infant mortality of iodination of irrigation water in a severely iodine-deficient area of China. The Lancet, 1997, 350: 771-773

13 Welch R M, Graham R D. Agriculture: The real nexus for enhancing bioavailable micronutrients in food crops. J Trace Elem Med, 2005, 18: 299-307

14 National Environmental Monitoring Centre of China. Background Value of Soil Elements in China (in Chinese). Beijing: China Environmental Science Press, 1990. 480

15 Hong C L, Weng H X, Yan A L, et al. The fate of exogenous iodine in pot soil cultivated with vegetables. Environ Geochem Health, 2009, 31: 99-108

16 Hong C L, Weng H X, Yan A L, et al. Dynamic characterization of iodine uptake in vegetables plants (in Chinese). Acta Ecol Sin, 2009, 29: $1438-1447$

17 Foster R C, Sands R. Response of radiate pine to salt stress. II. Localization of chloride. Aust J Plant Physiol, 1987, 4: 863-875

18 Weng H X, Yan A L, Hong C L, et al. Biogeochemical transfer and dynamics of iodine in a soil-plant system. Environ Geochem Health, 2009, 31: 401-411

19 Weng H X, Cai Q X. A manufacturing approach that contains iodine compound fertilizer (in Chinese). PCR Patent, ZL94108836, 19982-11

20 Weng H X, Weng J K, Yan A L, et al. Increment of iodine content in vegetable plants by applying iodine fertilizer and the residual characteristics of iodine in soil. Biol Trace Elem Res, 2008, 123: 218-228

21 Weigel H J, Jäger H J. Subcellular distribution and chemical form of cadmium in bean plants. Plant Physiol, 1980, 65: 480-482

22 Graham R, Senadhira D, Beebe S, et al. Breeding for micronutrient density in edible portions of staple food crops: Conventional approaches. Field Crops Res, 1999, 60: 57-80

23 Romarís H V, García S C, Barciela A M C, et al. Bioavailablity study using an in-vitro method of iodine and bromine in edible seaweed. Food Chem, 2011, 124: 1747-1752

24 Wu W H. Plant Physiology (in Chinese). Beijing: Science Press, 2003. 110

Open Access This article is distributed under the terms of the Creative Commons Attribution License which permits any use, distribution, and reproduction in any medium, provided the original author(s) and source are credited. 